\title{
Lack of replication of interactions between polymorphisms in rheumatoid arthritis susceptibility: case-control study
}

Aida Ferreiro-Iglesias ${ }^{1}$, Manuel Calaza ${ }^{1}$, Eva Perez-Pampin ${ }^{1}$, Francisco J Lopez Longo ${ }^{2}$, Jose L Marenco ${ }^{3}$, Francisco J Blanco ${ }^{4}$, Javier Narvaez ${ }^{5}$, Federico Navarro ${ }^{6}$, Juan D Cañete ${ }^{7}$, Arturo R de la Serna ${ }^{8}$, Isidoro Gonzalez-Alvaro ${ }^{9}$, Gabriel Herrero-Beaumont ${ }^{10}$, Jose L Pablos ${ }^{11}$, Alejandro Balsa ${ }^{12}$, Benjamin Fernandez-Gutierrez ${ }^{13}$, Rafael Caliz ${ }^{14}$, Juan J Gomez-Reino ${ }^{1,15}$ and Antonio Gonzalez ${ }^{1 *}$

\begin{abstract}
Introduction: Approximately 100 loci have been definitively associated with rheumatoid arthritis (RA) susceptibility. However, they explain only a fraction of RA heritability. Interactions between polymorphisms could explain part of the remaining heritability. Multiple interactions have been reported, but only the shared epitope (SE) $\times$ protein tyrosine phosphatase nonreceptor type 22 (PTPN22) interaction has been replicated convincingly. Two recent studies deserve attention because of their quality, including their replication in a second sample collection. In one of them, researchers identified interactions between PTPN22 and seven single-nucleotide polymorphisms (SNPs). The other showed interactions between the SE and the null genotype of glutathione S-transferase Mu 1 (GSTM1) in the anti-cyclic citrullinated peptide-positive $\left(\right.$ anti-CCP ${ }^{+}$) patients. In the present study, we aimed to replicate association with RA susceptibility of interactions described in these two high-quality studies.

Methods: A total of 1,744 patients with RA and 1,650 healthy controls of Spanish ancestry were studied. Polymorphisms were genotyped by single-base extension. SE genotypes of 736 patients were available from previous studies. Interaction analysis was done using multiple methods, including those originally reported and the most powerful methods described.

Results: Genotypes of one of the SNPs (rs4695888) failed quality control tests. The call rate for the other eight polymorphisms was $99.9 \%$. The frequencies of the polymorphisms were similar in RA patients and controls, except for PTPN22 SNP. None of the interactions between PTPN22 SNPs and the six SNPs that met quality control tests was replicated as a significant interaction term — the originally reported finding —or with any of the other methods. Nor was the interaction between GSTM1 and the SE replicated as a departure from additivity in anti-CCP ${ }^{+}$patients or with any of the other methods.
\end{abstract}

Conclusions: None of the interactions tested were replicated in spite of sufficient power and assessment with different assays. These negative results indicate that whether interactions are significant contributors to RA susceptibility remains unknown and that strict standards need to be applied to claim that an interaction exists.

\footnotetext{
* Correspondence: antonio.gonzalez.martinez-pedrayo@sergas.es

${ }^{1}$ Laboratorio Investigación 10 and Rheumatology Unit, Instituto de Investigacion Sanitaria, Hospital Clinico Universitario de Santiago, Travesia

Choupana, s/n, Santiago de Compostela 15706, Spain

Full list of author information is available at the end of the article
} 


\section{Introduction}

Progress in the genetics of complex diseases such as rheumatoid arthritis (RA) has been very rapid in the last decade [1]. Many loci have been discovered that are convincingly and reproducibly associated with susceptibility to these diseases. About 100 loci are associated with RA susceptibility at the genome-wide association study (GWAS) level [2]. However, the advance in genetics has also shown that there are still many remaining challenges. One that has been the focus of much discussion is the large fraction of the genetic component that is still unknown. This fraction has been dubbed as missing heritability that for most complex diseases is larger than $50 \%$ [3]. The exact magnitude of missing heritability is disputable because of ambiguity in the estimation of the total heritability that needs to be explained [4]. In a study estimating heritability from GWAS data, a method that is not affected by genetic interactions, but that is insensitive to low frequency causal loci, the 100 known non-human leukocyte antigen (non-HLA) loci account for $4.7 \%$ to $5.5 \%$ of RA heritability [2]. This fraction has been reported to be smaller (about 2.5\%) in twin studies [5], which are susceptible to confounding by genetic interactions but sensitive to low-frequency loci [4]. In addition, the large heterogeneity of RA adds to the ambiguity of the magnitude of missing heritability, as shown by the different genetic contributions of HLA shared epitope (SE) alleles in anti-cyclic citrullinated peptide-positive (anti-CCP ${ }^{+}$) patients $(18 \%)$ and in anti$\mathrm{CCP}^{-}$patients $(2.4 \%)$ [6]. Therefore, the missing heritability is very considerable in RA independently of the method used to estimate total heritability and the subgroup of patients being considered.

A variety of hypotheses have been proposed to explain the missing heritability [3], and there are already some studies in which researchers are exploring them in RA and other complex diseases [5,7-9]. One of these hypotheses is very compelling from a biological point of view. In that hypothesis, molecules, cells or tissues interact, and the outcome is often not fully predictable on the basis of consideration of the isolated factors. These ideas apply also to genes, whose products interact with the products of other genes and with the environment in gene $\times$ gene and gene $\times$ environment interactions, respectively. These interactions have been studied for a long time in genetics, but research in complex diseases has introduced in this field a strong incentive for more study together with the many difficulties typical of these diseases [10-13].

Interactions are invoked as a possible explanation for missing heritability because the combined effect of two genes can be larger than the sum of their individual contributions. In addition, genes that are not associated with disease susceptibility when considered in isolation can be associated in the presence of a modifier allele of other gene. Therefore, part of the missing heritability can be hidden in the form of interactions of known loci, because their contribution is considered one by one, as well as in loci not yet identified, because researchers in most GWASs have searched for associations singlenucleotide polymorphism (SNP) by SNP. It is also likely that the discovery of interactions will be of great utility for understanding the mechanisms of disease and to find very sensitive steps for therapeutic intervention. This hypothesis has driven multiple efforts to define types of interaction and their meaning and interpretation, as well as to develop tools to study them. Thanks to these efforts, there has been notable progress with tools that can be used to assess the association of all pairs of SNPs in a GWAS [14], as well as with statistical tests for interaction with increased sensitivity $[10,15,16]$. There has been also considerable clarification of the definitions and interpretation of the different types of interaction $[10,13]$.

Research in RA has had an important role in the recent progress in the study of interactions in complex diseases. It has led to the discovery of one of the most reproducible examples: interaction between HLA-DRB1 $\mathrm{SE}$ and protein tyrosine phosphatase nonreceptor type 22 (PTPN22) risk genotypes and with smoking in anti$\mathrm{CCP}^{+}$patients [17]. These interactions have been widely replicated [18-20] and also have introduced interaction as a departure from additivity, the less well-known type of interaction [21], to the complex disease genetics field. However, the progress in interaction analysis has not yet translated to frequent attempts to replicate previous findings; therefore, the multiple interactions in RA that have been reported in the main genetics and rheumatology journals [22-31] remain without confirmation.

We aimed to replicate sound studies of gene $\times$ gene interactions in the genetics of RA. We selected two studies that included both discovery of interaction and its replication in additional samples [22,23]. One of them included testing of many pairwise interactions, and therefore multiple tests, but the authors corrected for them by proceeding in four selection steps in three different sample collections [22]. This first study led to the identification of seven SNPs showing multiplicative interactions with PTPN22 that passed the four filters. In the second study, the authors analyzed only a gene $x$ gene interaction and included replication in a second collection of samples [23]. The null genotype of glutathione $S$-transferase $\mathrm{Mu} 1$ (GSTM1) showed additive interaction with the SE carrier genotype in the comparison of anti-CCP ${ }^{+}$and anti-CCP ${ }^{-}$patients. Our study did not replicate any of these interactions in spite of its sufficient power and the use of additional powerful tests. Therefore, we still need to find out how to improve reproducibility of interaction studies before knowing whether they are a significant contribution to RA susceptibility. 


\section{Methods \\ Participants}

DNA samples from patients with RA and healthy controls were obtained as described previously [32]. All participants were of European Spanish ancestry. Briefly, the study included a total of 1,744 patients classed with RA according to the 1987 American College of Rheumatology criteria [33] and 1,650 healthy controls. All recruiting centers applied a questionnaire that asked all participants about demographic data, including the origin of their progenitors. Those reporting a non-Spanish progenitor at any level were excluded. The Ethics Committee for Clinical Research of Galicia approved this study, and the ethics committees at the recruiting centers (listed in the Appendix) approved sample collection. All participants gave their written informed consent. Clinical data for the patients, including the anti-CCP and HLA-DRB1 genotypes of 736 patients, were extracted from their clinical records or from previous studies [20] (Table 1).

\section{Genotyping assays}

The RA-associated PTPN22 SNP rs2476601 (R620W) and the seven SNPs that have epistasis with it according to Briggs et al. [22], and an insertion/deletion polymorphism of exons 4 and 5 of GSTM1 determining the native and null alleles that interact with SE according to Mikuls et al. [23], were studied with single-base extension assays (SNaPshot Multiplex Kit; Life Technologies, Carlsbad, CA, USA) applied to the products of a multiplex PCR carried out with the KAPA2G Fast HotStart enzyme (Kapa Biosystems, Wilmington, MA, USA). Detailed protocols, as well as the sequences of

Table 1 Clinical features of the patients with rheumatoid arthritis $^{\mathrm{a}}$

\begin{tabular}{ll}
\hline Clinical characteristics & RA patients \\
\hline Women (\%) & 75.7 \\
Median age at disease onset (IQR) & 47 (37 to 57) \\
Morning stiffness (\%) & 96.2 \\
Arthritis in three or more joint areas (\%) & 99.7 \\
Arthritis of hand joints (\%) & 99.3 \\
Symmetric arthritis (\%) & 99.1 \\
Rheumatoid nodules (\%) & 20.3 \\
Rheumatoid factor (\%) & 71.2 \\
Erosions (\%) & 68.6 \\
Sicca syndrome (\%) & 8.9 \\
Interstitial pneumonitis (\%) & 2.7 \\
Shared epitope (carrier \%) & 55.0 \\
Anti-CCP (\%) & 67.3
\end{tabular}

${ }^{\mathrm{a}} \mathrm{CCP}$, Cyclic citrullinated peptide; RA, Rheumatoid arthritis. ${ }^{\mathrm{b}}$ Data were available for $<85 \%$ of the patients: 1,349 for age of disease onset, 1,283 for rheumatoid nodules and 736 for shared epitope and anti-CCP antibodies. primers and probes used for these assays, are available upon request. Only the GSTM1 polymorphism was uncommon, because, as in previous studies [23], it did not allow detection of heterozygous participants; only null homozygotes could be distinguished from carriers of native alleles. Quality control procedures used included manual revision of results, call rate $>90 \%$ for each polymorphism, fit of genotype frequencies with Hardy-Weinberg equilibrium (HWE) $(P>0.05)$, reproducibility $(>99 \%)$ tested by regenotyping $10 \%$ of the samples, and comparison of allele frequencies with those in HapMap and with those reported in other studies.

\section{Statistical analyses}

Allelic association of each polymorphism with RA susceptibility was assessed with $\chi^{2}$ tests. Replication of previously reported interactions was attempted first with the same statistical analysis used in the original study and afterward with alternative approaches. In this way, the multiplicative interaction between PTPN22 rs2476601 and each of the other seven SNPs described by Briggs et al. [22] was tested as the coefficient of the multiplicative interaction term of a logistic regression model that included the PTPN22 SNP and the interacting SNP coded according to a dominant model of their minor alleles. This coefficient is equal to the ratio of odds ratios of the interaction $\left(\mathrm{ROR}_{\mathrm{i}}\right)$. This analysis was done by comparing RA patients with controls; also, anti-CCP ${ }^{+}$patients were compared with healthy controls, because most patients in the Briggs et al. study were anti-CCP ${ }^{+}$. All the previous analyses were performed with STATISTICA software (StatSoft, Tulsa, OK, USA). In turn, interaction analysis between the GSTM1 null genotype and the SE was performed as described by Mikuls et al. [23]. That is, we compared anti- $\mathrm{CCP}^{+}$patients with anti-CCP ${ }^{-}$patients following a dominant model for the GSTM1 native and HLA-DRB1 SE alleles. The parameter analyzed was the attributable proportion (AP) to the interaction [21]. When AP is different from zero, it indicates the proportion of the association of the two loci that is attributable to departure from additivity. This analysis was done in $\mathrm{R}$ [34] using the Hosmer and Lemeshow approach [35].

The alternative approaches for analysis of the interaction included interchanging the analyses and other complementary tests-that is, testing the interactions used by Briggs et al. for departure from additivity and testing the relationship between the GSTM1 null genotype and SE as a multiplicative interaction. These tests were complemented with others. First, we tested multiplicative interactions with the same three-term logistic regression model, but with the polymorphisms coded according to an additive genetic model (codes 0,1 and 2 for the common allele homozygote, the heterozygote and the minor allele homozygote, respectively). Second, 
we used LRASSOC software to cover a range of saturated genetic models with and without interactions [36]. These models are built as logistic regression models, and the best model is selected by using Akaike's Information Criterion (AIC), which is more sensitive than a significant difference between models. Models having an AIC difference $<2$ are not meaningfully different. Third, we performed two tests that, according to recent comparative studies, are the most powerful for detecting multiplicative interaction between two loci in a series of scenarios, provided that the two loci are in linkage equilibrium $[15,16]$. The first was the chi-squared Pearson statistic $\left(\mathrm{T}_{\text {Pearson }}\right)$ in cases for independence of two loci [15]. The second was the adjusted $\mathrm{Wu}$ statistic for gametic phase disequilibrium in case-only analysis $\left(\mathrm{T}_{\mathrm{AWu} \text {-co }}\right)$ [16]. Power analysis was done applying the formula for power of $\mathrm{ROR}_{\mathrm{i}}[37]$.

\section{Results}

Genotyping assays for one of the SNPs (rs4695888, selected for its reported interaction with PTPN22) failed. The remaining polymorphisms were successfully assayed in $99.9 \%$ of the Spanish samples. Genotypes of all them fitted HWE $(P<0.05)$. Only PTPN22 rs2476601 of the SNPs from Briggs et al. was significantly associated with RA $\left(\mathrm{OR}=1.53,95 \% \mathrm{CI}=1.29\right.$ to $\left.1.80, P=4.61 \times 10^{-7}\right)$ (Table 2). Lack of association of the other SNPs was also the result in a previous report [22]. The GSTM1 null genotype, in turn, was not different between anti-CCP ${ }^{+}$ and anti-CCP ${ }^{-}$RA patients (Table 2, lower rows), whereas the SE was clearly more common in the anti$\mathrm{CCP}^{+}$patients than in the anti-CCP${ }^{-}$patients. These results are similar to those previously reported by Mikuls et al. [23].

\section{Lack of replication of epistasis with PTPN22 rs2476601}

We tested the reported epistasis between six SNPs and the PTPN22 rs2476601 SNP according to the original model: multiplicative interaction (evaluated as the interaction term of a logistic regression or its equivalent $\mathrm{ROR}_{\mathrm{i}}$ between the minor alleles following dominant inheritance [22]. These analyses did not replicate any of the six instances of epistasis (Table 3). Lack of replication was not attributable to lack of power, because the post hoc type II errors ( $\beta$ ) of missing results of a magnitude as the reported by Briggs et al. [22] at the final stage of their analyses were $<0.20$, which is conventionally considered sufficient (corresponding to statistical power of 0.80). The SNP with less power at the $\mathrm{ROR}_{\mathrm{i}}$ term was rs7726839 with post hoc $\beta=0.136$, whereas all others had post hoc $\beta<0.071$.

A lack of significant epistasis was observed, both with all patients and with anti-CCP ${ }^{+}$patients. The lack of replication of epistasis was not dependent on the type of specific test or interaction model, because we tested the six SNPs for multiplicative interaction with the PTPN22 rs2476601 SNP using several methods and none was positive (not shown). These tests included different genetic models in addition to the dominant one explored in the original report [22]. They also included the two tests reported as the most powerful in recent comparative studies $[15,16]$. In addition, we tested the six SNPs for interactions with PTPN22 in the alternative framework for interaction, as a departure from additivity, and obtained similar results. We should note that, in addition to not showing significant association, the $\mathrm{ROR}_{\mathrm{i}}$ of each of the six SNPs showed a nominal change in the opposite direction to the previously reported data (Figure 1).

Table 2 Association of polymorphisms with rheumatoid arthritis or anti-cyclic citrullinated peptide-positive rheumatoid arthritis ${ }^{a}$

\begin{tabular}{|c|c|c|c|c|c|c|}
\hline \multirow[b]{2}{*}{ SNP } & \multicolumn{2}{|l|}{ RA patients } & \multicolumn{2}{|l|}{ Controls } & \multirow[b]{2}{*}{$P$} & \multirow[b]{2}{*}{ OR $(95 \% \mathrm{Cl})$} \\
\hline & Genotype counts & $\overline{\text { MAF }}$ & Genotype counts & $\overline{\text { MAF }}$ & & \\
\hline PTPN22 rs2476601 & $1,383 / 325 / 35$ & 0.11 & $1,405 / 235 / 10$ & 0.08 & $4.61 \times 10^{-7}$ & $1.53(1.29$ to 1.8$)$ \\
\hline rs7726839 & $1,012 / 631 / 100$ & 0.24 & 959/592/88 & 0.23 & ns & 1.02 (0.91 to 1.14$)$ \\
\hline rs12573019 & $1,302 / 405 / 37$ & 0.14 & $1,264 / 359 / 27$ & 0.13 & ns & 1.11 (0.97 to 1.28$)$ \\
\hline rs1168587 & $652 / 830 / 260$ & 0.39 & $612 / 762 / 276$ & 0.40 & ns & 0.97 (0.87 to 1.05$)$ \\
\hline rs1895535 & $1,602 / 138 / 4$ & 0.04 & $1,503 / 137 / 7$ & 0.05 & ns & 0.91 (0.72 to 1.15$)$ \\
\hline rs7200573 & $940 / 687 / 116$ & 0.26 & $890 / 633 / 127$ & 0.27 & ns & 0.97 (0.87 to 1.08$)$ \\
\hline \multirow[t]{3}{*}{ rs11865624 } & $1,532 / 201 / 10$ & 0.06 & $1,424 / 221 / 3$ & 0.07 & ns & $0.92(0.76$ to 1.11$)$ \\
\hline & \multicolumn{2}{|l|}{ Anti-CCP ${ }^{+}$patients } & \multicolumn{2}{|l|}{ Anti-CCP ${ }^{-}$patients } & & \\
\hline & \multicolumn{2}{|l|}{ Positive/negative } & \multicolumn{2}{|l|}{ Positive/negative } & & \\
\hline SE & $279 / 174^{b}$ & & $116 / 153^{b}$ & & $1.69 \times 10^{-6}$ & 2.11 (1.56 to 2.88$)$ \\
\hline GSTM1 & $402 / 376^{c}$ & - & $186 / 192^{c}$ & - & ns & $1.10(0.86$ to 1.41$)$ \\
\hline
\end{tabular}

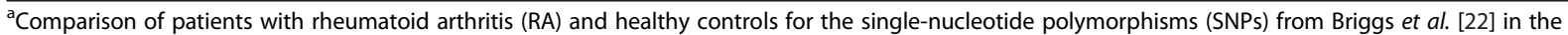
upper rows and comparison between anti-cyclic citrullinated peptide-positive (anti-CCP ${ }^{+}$) and anti-CPP ${ }^{-}$RA patients for shared epitope (SE) and glutathione S-transferase Mu 1 (GSTM1) in the lower rows. MAF, Minor allele frequency; ns, Not significant; PTPN22, Protein tyrosine phosphatase nonreceptor type 22. ${ }^{\mathrm{b}}$ Positive, SE carrier; negative, SE non-carrier. ${ }^{\mathrm{C} P o s i t i v e, ~ n a t i v e ~ c a r r i e r ; ~ n e g a t i v e, ~ n u l l ~ h o m o z y g o t e . ~}$ 
Table 3 Lack of replication of epistasis ${ }^{a}$ as the described by Briggs et al. [22]

\begin{tabular}{|c|c|c|c|c|c|c|}
\hline \multirow[t]{2}{*}{ SNP } & \multirow[t]{2}{*}{$\mathrm{ROR}_{\mathrm{i}}(95 \% \mathrm{Cl})$} & \multirow[t]{2}{*}{$P$} & \multirow{2}{*}{$\begin{array}{l}\text { SNP carriers } \\
\text { OR }_{\text {PTPN22 }}(95 \% \mathrm{Cl})\end{array}$} & \multirow{2}{*}{$\begin{array}{l}\text { SNP noncarriers } \\
\text { OR }_{\text {PTPN22 }}(95 \% \mathrm{Cl})\end{array}$} & \multicolumn{2}{|l|}{ Anti-CCP ${ }^{+}$patients } \\
\hline & & & & & $\mathrm{ROR}_{\mathrm{i}}(95 \% \mathrm{Cl})$ & $P$ \\
\hline rs7726839 & 1.08 (0.75 to 1.55$)$ & 0.70 & 1.56 (1.18 to 2.07$)$ & 1.45 (1.15 to 1.83$)$ & $1.23(0.8$ to 1.9$)$ & 0.34 \\
\hline rs12573019 & 0.74 (0.49 to 1.12 ) & 0.15 & 1.19 (0.83 to 1.71$)$ & 1.61 (1.31 to 1.98$)$ & 0.63 (0.38 to 1.04$)$ & 0.07 \\
\hline rs1168587 & 0.84 (0.58 to 1.22$)$ & 0.35 & 1.40 (1.11 to 1.76$)$ & 1.68 (1.24 to 2.24$)$ & 0.92 (0.59 to 1.43$)$ & 0.71 \\
\hline rs1895535 & 0.66 (0.36 to 1.20$)$ & 0.17 & 1.02 (0.58 to 1.80$)$ & 1.56 (1.25 to 1.92$)$ & 0.84 (0.39 to 1.8 ) & 0.66 \\
\hline rs 7200573 & 1.14 (0.8 to 1.63$)$ & 0.47 & 1.60 (1.24 to 2.07$)$ & 1.40 (1.10 to 1.80$)$ & $1.26(0.82$ to 1.93$)$ & 0.28 \\
\hline rs11865624 & 1.15 (0.68 to 1.94$)$ & 0.59 & 1.69 (1.04 to 2.75$)$ & 1.47 (1.21 to 1.78$)$ & 1.35 (0.72 to 2.53$)$ & 0.36 \\
\hline
\end{tabular}

a Data show lack of replication between the six single-nucleotide polymorphisms (SNPs) and the PTPN22 rheumatoid arthritis (RA) locus in the whole set of RA patients and controls (left) and in the comparison of anti-cyclic citrullinated peptide-positive (anti-CCP ${ }^{+}$) patients with controls (last two columns on the right). PTPN22, Protein tyrosine phosphatase nonreceptor type 22; $\mathrm{ROR}_{\mathrm{i}}$, Ratio of odds ratios of the interaction.

Lack of interaction between the null genotype of GSTM1 and the shared epitope

Interaction between the null genotype of GSTM1 and that carrying the SE has been described as a significant additive interaction in comparisons between anti-CCP ${ }^{+}$ and anti-CCP ${ }^{-}$patients with RA [23]. In our samples, there was no evidence of this interaction, as the AP was not significantly different from zero $(\mathrm{AP}=-0.05$, $95 \% \mathrm{CI}=-0.54$ to 0.44 ). None of the additional tests performed for deviations from additivity (relative excess risk due to interaction RERI and synergy [SI]) were significant, and neither were the tests used to assess multiplicative interactions (not shown), which were the same as those described in the previous subsection. In exploratory analysis, the OR for the patients with the GSTM1 native genotype and SE was identical to the OR for the patients with the GSTM1 null genotype and SE, reflecting the lack of increased association when the two risk genotypes were present (Table 4). Lack of sufficient power for replication was unlikely, because the sample sizes of the two collections of samples used by Mikuls et al. [23] were slightly smaller than those available to us (703 from the Veterans Affairs Rheumatoid Arthritis (VARA) registry and 610 from the Study of New-Onset Rheumatoid Arthritis (SONORA) sample set, compared to 721 in the present study). We applied analysis of

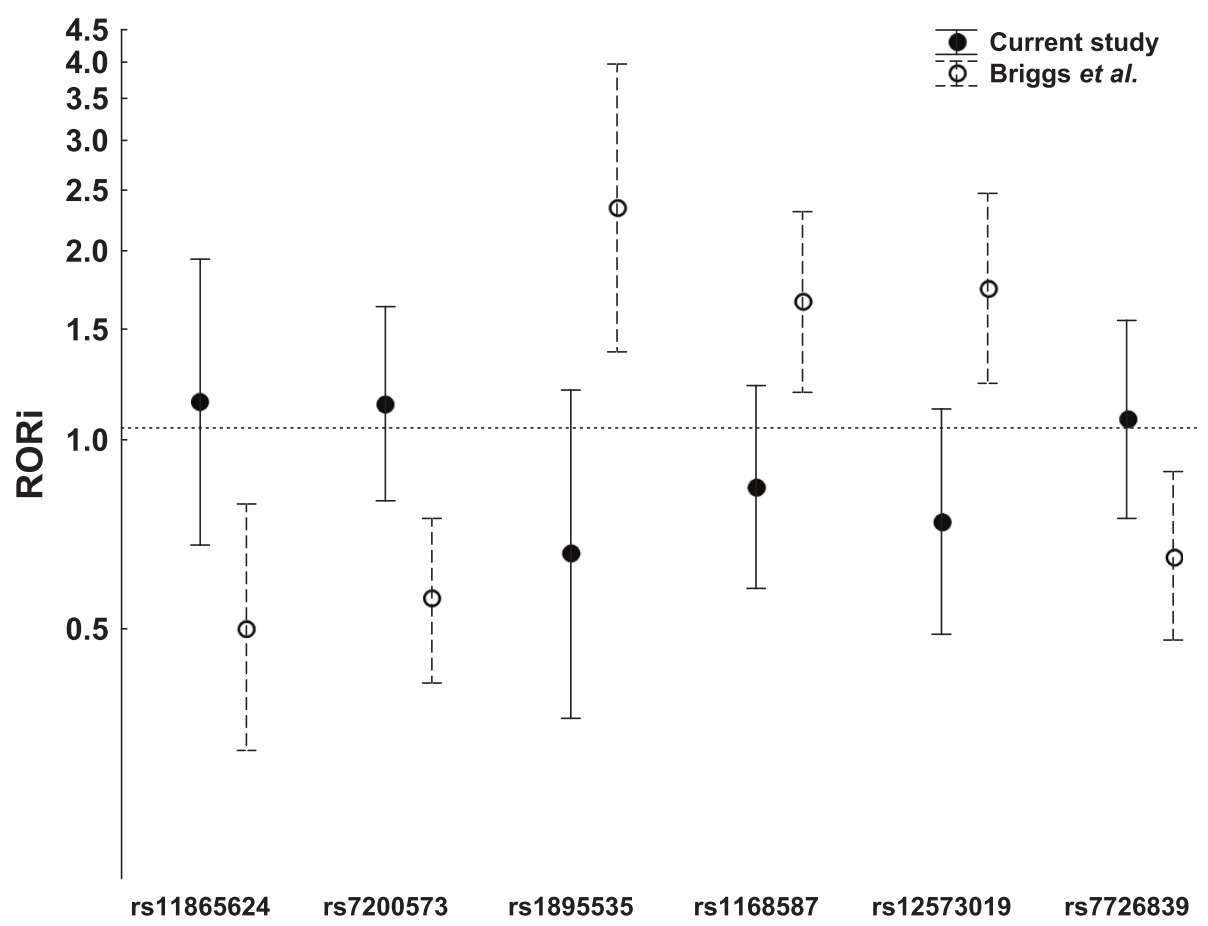

Figure 1 Comparison of the multiplicative interaction terms (ratio of odds ratios of the interaction) from the present study and from Briggs et al. [22]. None of the $95 \%$ Cls from Briggs et al. cross the 1.0 line, showing that they are significant. All the Cls from the present study cross this line and show a nominal opposite direction. ROR , Ratio of odds ratios of the interaction. 
Table 4 Analysis of interaction between GSTM1 genotype and HLA-DRB1 shared epitope carrier status in comparison of anti-CCP ${ }^{+}$with anti-CCP ${ }^{-}$rheumatoid arthritis patients ${ }^{\mathrm{a}}$

\begin{tabular}{lll}
\hline GSTM1/SE & Anti-CCP $^{+} /$anti-CCP $^{-}$( $\left.\boldsymbol{n}\right)$ & OR (95\% Cl) \\
\hline Native/SE & & Reference \\
Null/SE & $84 / 79$ & $1.14(1.77$ to 0.74$)$ \\
Native/SE $^{+}$ & $90 / 74$ & $2.26(1.46$ to 3.52$)$ \\
Null/SE $^{+}$ & $130 / 54$ & $2.25(1.46$ to 3.44$)$
\end{tabular}

${ }^{a} \mathrm{CCP}$, Cyclic citrullinated peptide; GSTM1, Glutathione S-transferase Mu 1; GSTM1 native, Carrier native; GSTM1 null, Homozygote null; SE, Shared epitope.

confidence intervals as a way to explore power issues $[38,39]$, owing to the lack of an analytical approach for estimating the power of AP. This analysis showed that our results were sufficient to exclude an interaction as the observed in the VARA sample, because the APs of the two studies fall outside the respective CIs (Figure 2). In contrast, our results were uncertain (neither excluding nor declaring them equivalent) in relation to the interaction observed in the SONORA sample, because the AP of the SONORA sample was within the CI of our study but the AP of our study is outside the CI of the SONORA sample (Figure 2).

\section{Discussion}

None of the seven interactions analyzed was replicated. This is very significant because (1) they have been reported in large studies that included replication in independent samples [22,23], and (2) our study is of sufficient power, we performed analyses for multiple inheritance and interaction models and we used the most powerful tests $[15,16]$. Therefore, we think our results raise questions about these interactions and, more generally, that they show how the level of reproducibility reached in RA association studies has yet to be achieved in interaction studies. As a consequence, only the previously known SE $\times$ PTPN22 interaction pertaining to anti-CCP ${ }^{+} \mathrm{RA}$ patients remains independently validated among the gene $\times$ gene interactions [17].

We attempted to replicate the Briggs et al. study where the authors have considered the whole genome for interactions with PTPN22 [22]. As such, the number of tests could be very large and led to many false positives, but the Briggs et al. study included four steps of filtering. In the first step, 512 multiplex RA families were studied with microsatellites covering the genome. This analysis led to suggestive evidence in 5 loci containing 10,589 SNPs of the GWAS platform. These SNPs were

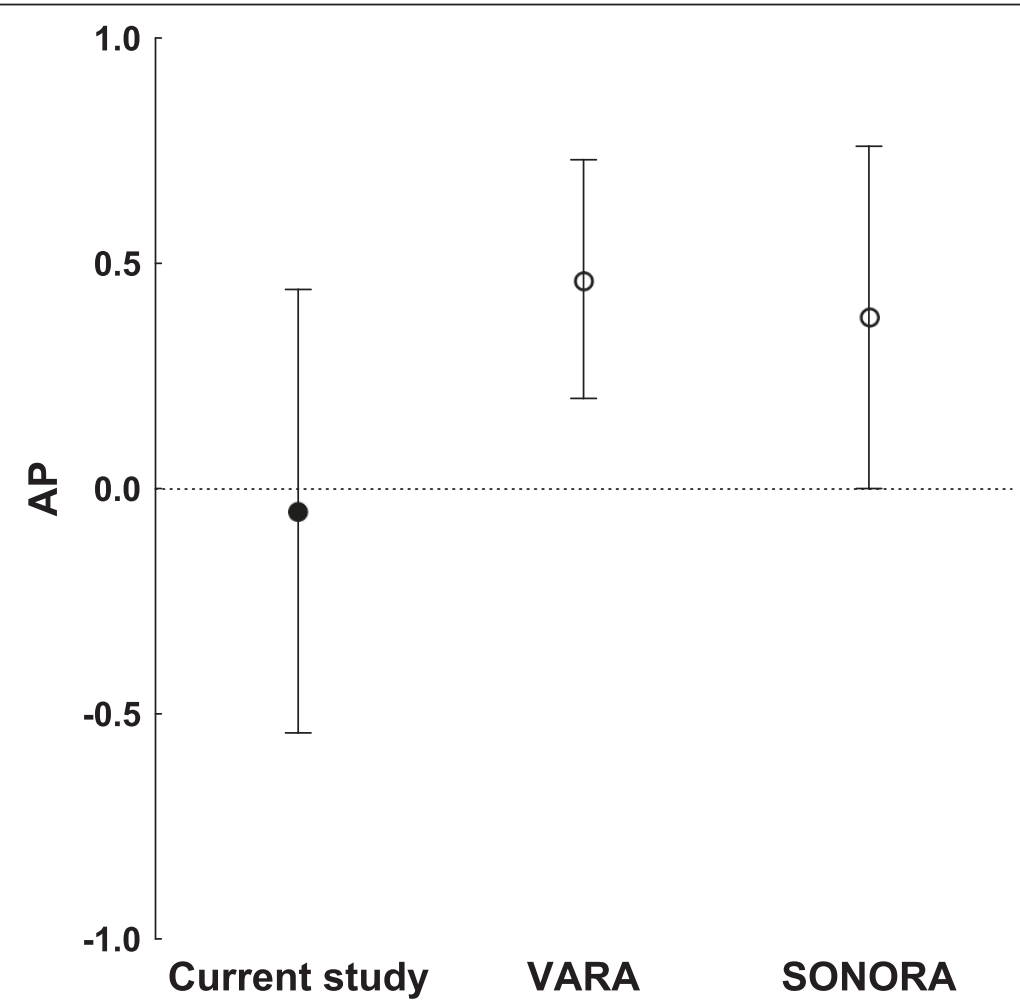

Figure 2 Comparison of attributable proportions to interactions. Graph depicts the attributable proportions to the interaction (APs) between the GSTM1-null genotype and shared epitope in anti-cyclic citrullinated peptide-positive rheumatoid arthritis patients in the present study and the two sample collections (Veterans Affairs Rheumatoid Arthritis (VARA) registry and Study of New-Onset Rheumatoid Arthritis (SONORA) sample set) included in the Mikuls et al. study [23]. 
tested in a case-control analysis ( $n=908$ cases/1,260 controls from the North American Rheumatoid Arthritis Consortium I (NARAC-I)) for significant heterogeneity of PTPN22 association in function of the SNP genotypes. The 665 SNPs showing significant heterogeneity were tested for multiplicative interaction in the subset of the NARAC-I sample with a more uniform Northern European ancestry. In this subset of 677 patients and 750 controls, the number of SNPs showing significant interaction was 449. These SNPs were tested again in an additional set of 947 patients and 1,756 controls (NARAC-II). Significant interactions were replicated for the seven SNPs we addressed in the present study. The least significant RORi showed a $P=6.1 \times 10^{-3}$ in the joint analysis of the two last case-control sets. Therefore, none of them was borderline significant; however, none was extremely significant, because the lower $P$-value was $1.5 \times 10^{-5}$. In retrospect, it seems likely that the multiple filters were not sufficient to eliminate false-positive results although they reduced them. This makes it necessary to consider that joint analysis of all available samples with a higher threshold of significance could be more efficient for interaction analysis, as it is for association studies [40].

The Mikuls et al. study was hypothesis-driven, and the researchers examined a single gene $\times$ gene interaction [23]. Their aim was to explore the null genotype of GSTM1 with regard to susceptibility to anti-CCP ${ }^{+} \mathrm{RA}$. The GSTM1 null allele determines a deletion of the glutathione $S$-transferase gene, coding for a ubiquitous enzyme facilitating elimination of reactive oxygen species conjugated to glutathione. The null genotype has been associated with higher oxidative stress and increased risk for smoking-related inflammatory diseases, including RA [41-43]. Therefore, the hypothesis of Mikuls and colleagues was that the null genotype of GSTM1 contributes to anti-CCP ${ }^{+} \mathrm{RA}$ where smoking is known to increase risk. Analysis of the 703 patients of the VARA collection showed additive interaction between the GSTM1 null genotype and SE when comparisons of the anti-CCP ${ }^{+}$with the anti-CCP ${ }^{-}$patients were made [23]. This result was replicated in the 610 patients of the SONORA study. Additive interactions are known between PTPN22 and $\mathrm{SE}$ and between $\mathrm{SE}$ and smoking in the anti-CCP${ }^{+}$ RA patients [17-20]. This type of interactions has been claimed to be more biologically relevant than multiplicative interactions $[17,21]$, although there is a lot of discussion about the meaning of any of them $[10,13]$. Therefore, Mikuls et al. apparently found an additional piece of the network of interacting factors leading to anti- $\mathrm{CCP}^{+} \mathrm{RA}$ [23]. However, it is noteworthy that they did not find interactions with smoking, which was another piece of the hypothesis and one that was relevant in other RA studies [41,43]. Our study did not replicate the interaction between
GSTM1 and SE in spite of the sufficient power and multiple tests for interaction.

It has been proposed that replicating gene $\times$ gene interactions is more difficult than replicating associations of individual SNPs. The additional difficulty is due in part to the study of polymorphisms that are not causal of the interaction, but only in linkage disequilibrium (LD) with the nongenotyped causal polymorphisms (markers or tags) [44]. The power of the replication is decreased by variation in the LD of the genotyped tag SNPs with the causal polymorphisms between the samples used for discovery and for replication. The reduction of power is proportional to the product of the decreasing LD between tag SNPs and the causal variants [44]. This factor is moderated in our study because PTPN22 rs2476601, the SE alleles and the null genotype of GSTM1 are causal polymorphisms, leaving no room for this effect in the interaction that was described by Mikuls et al. [23], and only for a linear decrease in power with the decrease in LD in the SNPs reported as interacting with PTPN22 [22]. Another factor contributing to the lack of reproducibility is heterogeneity between studies. However, genetic heterogeneity does not have a large impact in RA, where most loci are shared between Europeans and Asians [2]. Therefore, it is uncertain if the lower frequencies of carriers of PTPN22 rs2476601 and SE in our Spanish patients compared to patients in the previous studies conducted with participants of Northern European ancestry could have contributed to the discordant results (PTPN22 risk allele carriers in our RA patients $=20.7 \%$ vs. $27.8 \%$ and $27.3 \%$ in NARAC-I and NARAC-II, respectively, $P<10^{-4}$ for both comparisons; and $54.6 \%$ of SE carriers in our RA patients vs. $75.5 \%$ and $71.1 \%$ in the VARA and SONORA samples, $P<10^{-15}$ and $P<10^{-9}$, respectively). Another type of heterogeneity that decreases reproducibility is clinical heterogeneity. In this regard, within the available information, we note only a much rarer smoking habit in our patients than in the patients in the Mikuls et al. study $(20.6 \%$ of ever smokers among the RA patients we analyzed for this interaction vs. $79.8 \%$ and $65.1 \%$ in the VARA and SONORA cohorts, $P<10^{-93}$ and $P<10^{-50}$, respectively). Other differences, such as in the sex ratios, were observed only between our samples and one of the two collections used in the previous studies. Again, it is uncertain if the difference in smoking habit could impinge upon the results because no interaction between smoking and GSTM1 null genotype was detected by Mikuls et al. [23]; however, such an interaction was reported in a different RA study [41].

The negative results we have obtained are discouraging because we selected for replication studies that were prominent in their methods and results, and because there is a conflict between biologic concepts that include 
interaction and the results of searching for its footprint in association studies. There are many other studies in which researchers have reported significant gene $\times$ gene interactions in RA [24-31], but only the PTPN22 $\times \mathrm{SE}$ interaction in anti- $\mathrm{CCP}^{+}$patients has been independently replicated [17-20]. It has been a constant in the field to hope that better methods will allow discovery of prevalent interactions, but this hope has yet to be realized. Lack of reproducibility has also been observed between analyses of the same data with different approaches, as has happened with the Welcome Trust Case Control Consortium GWAS of seven complex diseases, including RA $[14,45,46]$, and with the NARAC GWASs [47-50]. Therefore, it is not attributable only to insufficient power of the studies. Over time, it is becoming evident that discovery of interactions is a standing challenge for the genetics of complex diseases. Until a solution is found, researchers have no better choice than to increase demands on the threshold for significance and on independent replication for the assessment of interaction findings. It is to be expected that these measures will help to uncover the contribution that interactions have on the genetic components of RA and how these components work.

\section{Conclusion}

No new gene $\times$ gene interactions in the susceptibility to RA have been independently replicated beyond the interaction between the SE and the risk allele of PTPN22. Our selection of two sound studies for replication led to negative results. The lack of interaction was found in spite of sufficient power and thorough analysis. This situation is unsatisfactory because interactions are widespread in biological systems, and they could help answer many questions, including the heritability not explained by known disease loci. Our negative results show that the contribution of genetic interactions to RA susceptibility still cannot be assessed and that strict standards for claiming interactions need to be applied.

\section{Appendix}

The following ethics committees approved sample collection and this study: Comité Ético de Investigación Clínica de Galicia (currently, Comité Autonómico de Ética de la Investigación de Galicia), Comité Ético de Investigación Clínica del Instituto de Investigación Sanitaria Gregorio Marañón, Comité Ético de Investigación Clínica del Hospital Universitario Nuestra Señora de Valme, Comité Ético de Investigación Clínica de la Ciutat Sanitària i Universitària de Bellvitge, Comité Ético de Investigación Clínica del Hospital Universitario Virgen Macarena, Comité Ético de Investigación Clínica del Hospital Clínic i Provincial de Barcelona, Comité de Ética de la Investigación Clínica Fundación de Gestión Sanitaria del Hospital de la Santa Creu i Sant Pau, Comité Ético de Investigación Clínica del Hospital Universitario de La Princesa, Comité Ético de Investigación Clínica de la Fundación Jiménez Díaz, Comité Ético de Investigación Clínica del Hospital 12 de Octubre, Comité Ético de Investigación Clínica del Hospital Clínico San Carlos, and Comité Ético de Investigación Clínica del Hospital Universitario Virgen de las Nieves.

\begin{abstract}
Abbreviations
AIC: Akaike's Information Criterion; Anti-CCP: Anti-cyclic citrullinated peptide; AP: Attributable proportion; Cl: Confidence interval; GSTM1: Glutathione S-transferase Mu 1; GWAS: Genome-wide association study; HLA: Human leukocyte antigen; HWE: Hardy-Weinberg equilibrium; LD: Linkage disequilibrium; NARAC: North American Rheumatoid Arthritis Consortium; PTPN22: Protein tyrosine phosphatase nonreceptor type 22; RA: Rheumatoid arthritis; ROR: Ratio of odds ratios of interaction; SE: Shared epitope; SNP: Single-nucleotide polymorphism; SONORA: Study of New-Onset Rheumatoid Arthritis; VARA: Veterans Affairs Rheumatoid Arthritis.
\end{abstract}

\section{Competing interests}

The authors declare that they have no competing interests.

\section{Authors' contributions}

AFI designed the study, genotyped the samples, analyzed the data and wrote the first manuscript draft. EPP, FJLL, JLM, FJB, JN, FN, JC, ARS, IGA, GHB, $J \mathrm{P}, A B, B F G$ and $R C$ provided the samples and clinical and demographic information of the patients. MC analyzed data. JJGR managed the collection of samples and data and provided the samples and clinical and demographic information of the patients. AG designed the study, managed the collection of samples and data, analyzed the data, wrote the first manuscript draft, obtained funding and supervised the study. All authors read and approved the final manuscript.

\section{Acknowledgements}

We thank Carmen Pena-Pena for technical help in genotyping and managing samples. This work was funded by Fondo de Investigacion Sanitaria of the Instituto de Salud Carlos III (Spain) grants 11/01048 and 12/01909 and by RETICS Program RD12/0009/0008, which are partially financed by the European Regional Development Fund of the European Union.

\section{Author details}

${ }^{1}$ Laboratorio Investigación 10 and Rheumatology Unit, Instituto de Investigacion Sanitaria, Hospital Clinico Universitario de Santiago, Travesia Choupana, s/n, Santiago de Compostela 15706, Spain. ${ }^{2}$ Rheumatology Unit, Hospital Universitario Gregorio Marañon, Calle Doctor Esquerdo, 46, Madrid 28009, Spain. ${ }^{3}$ Rheumatology Unit, Hospital Universitario de Valme, Av de Bellavista, s/n, Sevilla 41014, Spain. ${ }^{4}$ Rheumatology Unit, INIBIC-CH Universitario A Coruña, As Xubias, 84, A Coruña 15006, Spain. ${ }^{5}$ Rheumatology Department, Hospital Universitario de Bellvitge, Feixa Llarga, s/n, Barcelona 08907, Spain. ${ }^{6}$ Rheumatology Unit, Hospital Universitario Virgen Macarena, Avd. Dr. Fedriani, 3, Sevilla 41009, Spain. ${ }^{7}$ Rheumatology Department, Hospital Clinic and IDIBAPS, Villarroel, 170, Barcelona 08036, Spain. ${ }^{8}$ Rheumatology Unit, Hospital Santa Creu e San Pau, Carrer de Sant Quintí, 89, Barcelona 08025, Spain. ${ }^{9}$ Rheumatology Service, Instituto de Investigación Sanitaria Hospital La Princesa, Hospital Universitario de La Princesa, Calle de Diego Leon, 62, Madrid 28006, Spain. ${ }^{10}$ Rheumatology Unit. Fundación Jiménez Díaz, Avda. Reyes Católicos, 2, Madrid 28040, Spain. ${ }^{11}$ Servicio de Reumatologia, Instituto de Investigación Hospital 12 de Octubre, Avda de Córdoba, s/n, Madrid 28041, Spain. ${ }^{12}$ Rheumatology Unit, Hospital La Paz, Paseo de la Castellana, 261, Madrid 28046, Spain. ${ }^{13}$ Rheumatology Unit, Hospital Clínico San Carlos, Calle Profesor Martín Lagos, s/n, Madrid 28040, Spain. ${ }^{14}$ Hospital Vírgen de las Nieves, Av de las Fuerzas Armadas, 2, Granada 18014, Spain. ${ }^{15}$ Department of Medicine, Universidad de Santiago de Compostela, Travesia Choupana, s/n, Santiago de Compostela 15706, Spain.

Received: 24 March 2014 Accepted: 21 August 2014

Published online: 27 September 2014 


\section{References}

1. Altshuler D, Daly MJ, Lander ES: Genetic mapping in human disease. Science 2008, 322:881-888.

2. Okada Y, Wu D, Trynka G, Raj T, Terao C, Ikari K, Kochi Y, Ohmura K, Suzuki A, Yoshida S, Graham RR, Manoharan A, Ortmann W, Bhangale T, Denny JC, Carroll RJ, Eyler AE, Greenberg JD, Kremer JM, Pappas DA, Jiang L, Yin J, Ye L, Su DF, Yang J, Xie G, Keystone E, Westra HJ, Esko T, Metspalu A, et al: Genetics of rheumatoid arthritis contributes to biology and drug discovery. Nature 2014, 506:376-381.

3. Manolio TA, Collins FS, Cox NJ, Goldstein DB, Hindorff LA, Hunter DJ, McCarthy MI, Ramos EM, Cardon LR, Chakravarti A, Cho JH, Guttmacher AE, Kong A, Kruglyak L, Mardis E, Rotimi CN, Slatkin M, Valle D, Whittemore AS, Boehnke M, Clark AG, Eichler EE, Gibson G, Haines JL, Mackay TFC, McCarroll SA, Visscher PM: Finding the missing heritability of complex diseases. Nature 2009, 461:747-753.

4. Zuk O, Hechter E, Sunyaev SR, Lander ES: The mystery of missing heritability: genetic interactions create phantom heritability. Proc Natl Acad Sci U S A 2012, 109:1193-1198.

5. Stahl EA, Wegmann D, Trynka G, Gutierrez-Achury J, Do R, Voight BF, Kraft P, Chen R, Kallberg HJ, Kurreeman FA, Diabetes Genetics Replication and Meta-analysis Consortium, Myocardial Infarction Genetics Consortium, Kathiresan S, Wijmenga C, Gregersen PK, Alfredsson L, Siminovitch KA, Worthington J, de Bakker PI, Raychaudhuri S, Plenge RM: Bayesian inference analyses of the polygenic architecture of rheumatoid arthritis. Nat Genet 2012, 44:483-489.

6. van der Woude D, Houwing-Duistermaat JJ, Toes RE, Huizinga TW Thomson W, Worthington J, van der Helm-van Mil AH, de Vries RR: Quantitative heritability of anti-citrullinated protein antibody-positive and anti-citrullinated protein antibody-negative rheumatoid arthritis. Arthritis Rheum 2009, 60:916-923.

7. Hunt KA, Mistry V, Bockett NA, Ahmad T, Ban M, Barker JN, Barrett JC, Blackburn H, Brand O, Burren O, Capon F, Compston A, Gough SC, Jostins L, Kong Y, Lee JC, Lek M, MacArthur DG, Mansfield JC, Mathew CG, Mein CA, Mirza M, Nutland S, Onengut-Gumuscu S, Papouli E, Parkes M, Rich SS, Sawcer S, Satsangi J, Simmonds MJ, et al: Negligible impact of rare autoimmune-locus coding-region variants on missing heritability. Nature 2013, 498:232-235.

8. Diogo D, Kurreeman F, Stahl EA, Liao KP, Gupta N, Greenberg JD, Rivas MA, Hickey B, Flannick J, Thomson B, Guiducci C, Ripke S, Adzhubey I, Barton A, Kremer JM, Alfredsson L, Consortium of Rheumatology Researchers of North America Rheumatoid Arthritis Consortium International, Sunyaev S, Martin J, Zhernakova A, Bowes J, Eyre S, Siminovitch KA, Gregersen PK, Worthington J, Klareskog L, Padyukov L, Raychaudhuri S, Plenge RM: Rare, low-frequency, and common variants in the protein-coding sequence of biological candidate genes from GWASs contribute to risk of rheumatoid arthritis. Am J Hum Genet 2013, 92:15-27.

9. The Wellcome Trust Case Control Consortium, Craddock N, Hurles ME, Cardin N, Pearson RD, Plagnol V, Robson S, Vukcevic D, Barnes C, Conrad DF, Giannoulatou E, Holmes C, Marchini JL, Stirrups K, Tobin MD, Wain LV, Yau C, Aerts J, Ahmad T, Andrews TD, Arbury H, Attwood A, Auton A, Ball SG, Balmforth AJ, Barrett JC, Barroso I, Barton A, Bennett AJ, Bhaskar S, et al: Genome-wide association study of CNVs in 16,000 cases of eight common diseases and 3,000 shared controls. Nature 2010, 464:713-720.

10. Cordell HJ: Detecting gene-gene interactions that underlie human diseases. Nat Rev Genet 2009, 10:392-404.

11. Culverhouse R, Suarez BK, Lin J, Reich T: A perspective on epistasis: limits of models displaying no main effect. Am J Hum Genet 2002, 70:461-471.

12. Moore JH, Williams SM: Epistasis and its implications for personal genetics. Am J Hum Genet 2009, 85:309-320.

13. Wang $X$, Elston RC, Zhu X: The meaning of interaction. Hum Hered 2010, 70:269-277.

14. Liu Y, Xu H, Chen S, Chen X, Zhang Z, Zhu Z, Qin X, Hu L, Zhu J, Zhao GP, Kong X: Genome-wide interaction-based association analysis identified multiple new susceptibility loci for common diseases. PLOS Genet 2011, 7:e1001338.

15. Hu JK, Wang $X$, Wang P: Testing gene-gene interactions in genome wide association studies. Genet Epidemiol 2014, 38:123-134.

16. Ueki M, Cordell HJ: Improved statistics for genome-wide interaction analysis. PLoS Genet 2012, 8:e1002625.
17. Kallberg H, Padyukov L, Plenge RM, Ronnelid J, Gregersen PK, van der Helm-van Mil AH, Toes RE, Huizinga TW, Klareskog L, Alfredsson L, the Epidemiological Investigation of Rheumatoid Arthritis (EIRA) Study Group: Gene-gene and gene-environment interactions involving HLA-DRB1, PTPN22, and smoking in two subsets of rheumatoid arthritis. Am J Hum Genet 2007, 80:867-875.

18. Morgan AW, Thomson W, Martin SG, Yorkshire Early Arthritis Register Consortium, Carter AM, UK Rheumatoid Arthritis Genetics Consortium, Erlich HA, Barton A, Hocking L, Reid DM, Harrison P, Wordsworth P, Steer S, Worthington J, Emery P, Wilson AG, Barrett JH: Reevaluation of the interaction between HLA-DRB1 shared epitope alleles, PTPN22, and smoking in determining susceptibility to autoantibody-positive and autoantibody-negative rheumatoid arthritis in a large UK Caucasian population. Arthritis Rheum 2009, 60:2565-2576.

19. Mahdi H, Fisher BA, Källberg H, Plant D, Malmström V, Rönnelid J, Charles P, Ding B, Alfredsson L, Padyukov L, Symmons DP, Venables PJ, Klareskog L, Lundberg K: Specific interaction between genotype, smoking and autoimmunity to citrullinated a-enolase in the etiology of rheumatoid arthritis. Nat Genet 2009, 41:1319-1324.

20. Montes A, Dieguez-Gonzalez R, Perez-Pampin E, Calaza M, Mera-Varela A, Gomez-Reino JJ, Gonzalez A: Particular association of clinical and genetic features with autoimmunity to citrullinated a-enolase in rheumatoid arthritis. Arthritis Rheum 2011, 63:654-661. A published erratum appears in Arthritis Rheum 2011, 63:938.

21. Rothman KJ, Greenland S, Walker AM: Concepts of interaction. Am J Epidemiol 1980, 112:467-470.

22. Briggs FBS, Ramsay PP, Madden E, Norris JM, Holers VM, Mikuls TR, Sokka T, Seldin MF, Gregersen PK, Criswell LA, Barcellos LF: Supervised machine learning and logistic regression identifies novel epistatic risk factors with PTPN22 for rheumatoid arthritis. Genes Immun 2010, 11:199-208.

23. Mikuls TR, Gould KA, Bynoté KK, Yu F, LeVan TD, Thiele GM, Michaud KD, O'Dell JR, Reimold AM, Hooker R, Caplan L, Johnson DS, Kerr G, Richards JS, Cannon GW, Criswell LA, Noble JA, Bridges SL Jr, Hughes L, Gregersen PK: Anticitrullinated protein antibody (ACPA) in rheumatoid arthritis: influence of an interaction between HLA-DRB1 shared epitope and a deletion polymorphism in glutathione $\mathrm{S}$-transferase in a cross-sectional study. Arthritis Res Ther 2010, 12:R213.

24. Martínez A, Sánchez E, Valdivia A, Orozco G, López-Nevot MA, PascualSalcedo D, Balsa A, Fernández-Gutiérrez B, de la Concha EG, García-Sánchez A, Koeleman BP, Urcelay E, Martín J: Epistatic interaction between FCRL3 and NFKB1 genes in Spanish patients with rheumatoid arthritis. Ann Rheum Dis 2006, 65:1188-1191.

25. Newman WG, Zhang Q, Liu X, Walker E, Ternan H, Owen J, Johnson B, Greer W, Mosher DP, Maksymowych WP, Bykerk VP, Keystone EC, Amos Cl, Siminovitch KA: Rheumatoid arthritis association with the FCRL3-169C polymorphism is restricted to PTPN22 1858 T-homozygous individuals in a Canadian population. Arthritis Rheum 2006, 54:3820-3827.

26. Julia A, Moore J, Miquel L, Alegre C, Barcelo P, Ritchie M, Marsal S: Identification of a two-loci epistatic interaction associated with susceptibility to rheumatoid arthritis through reverse engineering and multifactor dimensionality reduction. Genomics 2007, 90:6-13.

27. Marinou I, Walters K, Dickson MC, Binks MH, Bax DE, Wilson AG: Evidence of epistasis between interleukin 1 and selenoprotein-S with susceptibility to rheumatoid arthritis. Ann Rheum Dis 2009, 68:1494-1497.

28. Bang SY, Han TU, Choi CB, Sung YK, Bae SC, Kang C: Peptidyl arginine deiminase type IV (PAD/4) haplotypes interact with shared epitope regardless of anti-cyclic citrullinated peptide antibody or erosive joint status in rheumatoid arthritis: a case control study. Arthritis Res Ther 2010, 12:R115

29. Perdigones N, Vigo AG, Lamas JR, Martínez A, Balsa A, Pascual-Salcedo D, de la Concha EG, Fernández-Gutiérrez B, Urcelay E: Evidence of epistasis between TNFRSF14 and TNFRSF6B polymorphisms in patients with rheumatoid arthritis. Arthritis Rheum 2010, 62:705-710.

30. Seddighzadeh M, Korotkova M, Källberg H, Ding B, Daha N, Kurreeman FA, Toes RE, Huizinga TW, Catrina Al, Alfredsson L, Klareskog L, Padyukov L: Evidence for interaction between 5-hydroxytryptamine (serotonin) receptor $2 \mathrm{~A}$ and $\mathrm{MHC}$ type II molecules in the development of rheumatoid arthritis. Eur J Hum Genet 2010, 18:821-826.

31. Eyre S, Bowes J, Diogo D, Lee A, Barton A, Martin P, Zhernakova A, Stahl E, Viatte S, McAllister K, Amos Cl, Padyukov L, Toes RE, Huizinga TW, Wijmenga C, Trynka G, Franke L, Westra HJ, Alfredsson L, Hu X, Sandor C, 
de Bakker PI, Davila S, Khor CC, Heng KK, Andrews R, Edkins S, Hunt SE, Langford C, Symmons D, et al: High-density genetic mapping identifies new susceptibility loci for rheumatoid arthritis. Nat Genet 2012, 44:1336-1340

32. Dieguez-Gonzalez R, Calaza M, Perez-Pampin E, de la Serna AR, FernandezGutierrez B, Castañeda S, Largo R, Joven B, Narvaez J, Navarro F, Marenco JL, Vicario JL, Blanco FJ, Fernandez-Lopez JC, Caliz R, Collado-Escobar MD, Carreño L, Lopez-Longo J, Cañete JD, Gomez-Reino JJ, Gonzalez A: Association of interferon regulatory factor 5 haplotypes, similar to that found in systemic lupus erythematosus, in a large subgroup of patients with rheumatoid arthritis. Arthritis Rheum 2008, 58:1264-1274.

33. Arnett FC, Edworthy SM, Bloch DA, MCShane DJ, Fries JF, Cooper NS, Healey LA, Kaplan SR, Liang MH, Luthra HS, Medsger TA Jr, Mitchell DM, Neustadt DH, Pinals RS, Schaller JG, Sharp JT, Wilder RL, Hunder GG: The American Rheumatism Association 1987 revised criteria for the classification of rheumatoid arthritis. Arthritis Rheum 1988, 31:315-324.

34. The R Project for Statistical Computing: R: A Language and Environment for Statistical Computing. [http://www.r-project.org]

35. Hosmer DW, Lemeshow S: Confidence interval estimation of interaction. Epidemiology 1992, 3:452-456.

36. North BV, Curtis D, Sham PC: Application of logistic regression to casecontrol association studies involving two causative loci. Hum Hered 2005, 59:79-87.

37. Marshall SW: Power for tests of interaction: effect of raising the type I error rate. Epidemiol Perspect Innov 2007, 4:4

38. Colegrave N, Ruxton GD: Confidence intervals are a more useful complement to nonsignificant tests than are power calculations. Behav Ecol 2003, 14:446-447.

39. Hoenig JM, Heisey DM: The abuse of power. Am Stat 2001, 55:19-24.

40. Skol AD, Scott $\sqcup$, Abecasis $G R$, Boehnke M: Joint analysis is more efficient than replication-based analysis for two-stage genome-wide association studies. Nat Genet 2006, 38:209-213. A published erratum appears in Nat Genet 2006, 38:390.

41. Criswell LA, Saag KG, Mikuls TR, Cerhan JR, Merlino LA, Lum RF, Pfeiffer KA, Woehl B, Seldin MF: Smoking interacts with genetic risk factors in the development of rheumatoid arthritis among older Caucasian women. Ann Rheum Dis 2006, 65:1163-1167.

42. Keenan BT, Chibnik LB, Cui J, Ding B, Padyukov L, Kallberg H, Bengtsson C, Klareskog L, Alfredsson L, Karlson EW: Effect of interactions of glutathione S-transferase $\mathrm{T} 1, \mathrm{M} 1$, and $\mathrm{P} 1$ and $\mathrm{HMOX} 1$ gene promoter polymorphisms with heavy smoking on the risk of rheumatoid arthritis. Arthritis Rheum 2010, 62:3196-3210.

43. Lundström E, Hartshorne T, Li K, Lindblad S, Wick MC, Bengtsson C, Alfredsson L, Klareskog L, Padyukov L: Effects of GSTM1 in rheumatoid arthritis; results from the Swedish EIRA study. PLoS One 2011, 6:e17880.

44. Ma L, Clark AG, Keinan A: Gene-based testing of interactions in association studies of quantitative traits. PLOS Genet 2013, 9:e1003321.

45. Wan X, Yang C, Yang Q, Xue H, Tang NL, Yu W: MegaSNPHunter: a learning approach to detect disease predisposition SNPs and high level interactions in genome wide association study. BMC Bioinformatics 2009, 10:13.

46. Yang $C$, He Z, Wan X, Yang Q, Xue H, Yu W: SNPHarvester: a filteringbased approach for detecting epistatic interactions in genome-wide association studies. Bioinformatics 2009, 25:504-511.

47. Sengupta Chattopadhyay A, Hsiao CL, Chang CC, Lian IB, Fann CS: Summarizing techniques that combine three non-parametric scores to detect disease-associated 2-way SNP-SNP interactions. Gene 2014, 533:304-312.

48. Clarke GM, Pettersson FH, Morris AP: A comparison of case-only designs for detecting gene $\times$ gene interaction in rheumatoid arthritis using genome-wide case-control data in Genetic Analysis Workshop 16. BMC Proc 2009, 3(Suppl 7):S73.
49. Cui X, Sha Q, Zhang S, Chen HS: A combinatorial approach for detecting gene-gene interaction using multiple traits of Genetic Analysis Workshop 16 rheumatoid arthritis data. BMC Proc 2009, 3(Suppl 7):S43.

50. D'Angelo GM, Rao D, Gu CC: Combining least absolute shrinkage and selection operator (LASSO) and principal-components analysis for detection of gene-gene interactions in genome-wide association studies. BMC Proc 2009, 3(Suppl 7):S62.

doi:10.1186/s13075-014-0436-x

Cite this article as: Ferreiro-lglesias et al.: Lack of replication of interactions between polymorphisms in rheumatoid arthritis susceptibility: case-control study. Arthritis Research \& Therapy 2014 16:436.

\section{Submit your next manuscript to BioMed Central and take full advantage of:}

- Convenient online submission

- Thorough peer review

- No space constraints or color figure charges

- Immediate publication on acceptance

- Inclusion in PubMed, CAS, Scopus and Google Scholar

- Research which is freely available for redistribution

Submit your manuscript at www.biomedcentral.com/submit
C Biomed Central 